\title{
THE USE OF MOTHER TONGUE IN INSTRUCTION: PUPILS' PERFORMANCE ACROSS THE YEARS
}

\author{
*Juliet S. Trujillo
}

Paper Received: 17.04.2020 / Paper Accepted: 26.05.2020 / Paper Published: 29.05.2020

Corresponding Author: Juliet S. Trujillo; Email: julietstrujillo@ gmail.com; doi:10.46360/globus.xxxxxxxx

\begin{abstract}
Language contributes to the meaningful and participative learning environment for children. thus the main purpose of this study is to determine the pupils' performance using the mother tongue as medium of instruction for the three consecutive academic years starting 2015-2016, 2016-2017 and 2017-2018 in the Division of La Carlota City, Negros Occidental, Philippines. Specifically, it determines the perceived effects of using mother tongue to the pupils' performance as assessed by their teachers; and the challenges encountered by the teachers in using the mother tongue in delivering the instruction. This study used mixed methods in gathering the data. In the quantitative approach, documents of 27 pupils analyzed using the mean percentage scores to determine their performance in various subjects with the mother tongue as medium of instruction. In qualitative, ten teacher participants who are the implementers of the native language were involved in a focus group discussion (FGD). The findings showed that improvement in pupils' cognitive, motor skills, and affective ability observed for three consecutive years of the implementation of the mother tongue. Teachers' general views of challenges were lack of instructional materials in the teaching mother tongue, lack of translated terms, and programmed training. Nevertheless, these did not hinder them from delivering quality instruction. It recommended that higher education must strengthen its curriculum in primary school to produce resourceful, innovative, and well-rounded teachers in teaching mother-tongue.
\end{abstract}

Keywords: Use of Mother Tongue; Instruction: Pupils' Academic Performance; Philippines.

\section{Introduction}

Language in education plays a vital role in the successful teaching-learning process. The students' dialect enables them to express themselves easily with no fear of making mistakes. In the Philippines, dialects and diverse culture of the people complicates the formation of language policy in education. According to Lewis, Simons, \& Fenning (2013), the Philippines experiences difficulties in implementing a language policy due to its more than 7000 islands and 181 distinct languages. The Bilingual Education Policy requires the use of the learners native language during the instruction in all subjects from kindergarten to grade three with Filipino and English taught as separate subjects (Philippines Department of Education, 2009). Followed by another order that offered more specific guidelines for MTB-MLE and embedded the reform in the newly adopted -K to 12 Basic Education Program (Philippines Department of Education, 2012). Until recently, the Enhanced Basic Education Act approved by the legislative body. This law requires the learning process, teaching materials, and evaluation to be in the mother tongue or native language from kindergarten through grade three with a mother language transition program from classes four through six.

According to Burton (2013), this shift in language policy is part of a growing trend around the world to support mother-tongue instruction in the early years of a child's education. Hence, the Philippines implemented the MTB-MLE. The role of language is the most important in the educational process. The effectiveness of this process is dependent on the existence of effective communication between teachers and students.

*Carlos Hilado Memorial State College-Alijis Campus, Bacolod City, Negros Occidental, Region VI, Philippines. 
A recent review of research reports on language and literacy concludes that becoming literate and fluent in one's first language is essential for overall communication and cognitive development, as well as academic achievement (Ball, 2010). In Vietnam, 68\% of grade one students in a mother tongue program achieved the level of "excellent" compared to only $28 \%$ of students not learning in their mother tongue (UNICEF, 2011).

Although there is abundant evidence regarding the efficacy of the use of MTB in improving the reading acquisition and subject-based knowledge, there is no research conducted on pupils' performance with the use of mother tongue for the three consecutive years of the full implementation in the Philippine educational system.

\section{Statement of The Problem}

The primary purpose of this study was to determine the pupils' performance using the mother tongue as medium of instruction for the three consecutive academic years starting 2015-2016, 2016-2017 and 2017-2018 in the Division of La Carlota City, Negros Occidental.

Specifically, it aimed to answer the following statements:

1. To determine the academic performance of pupils during the academic year, 2015-2016, 20162017, 2017-2018.

2. To determine the perceived effects of using mother tongue as medium of instruction to the pupil's performance as assessed by their teachers.
3. To determine the challenges encountered by the teachers in using the mother tongue as a medium of instruction.

\section{Theoretical Framework}

The theoretical framework adopted in this study derived from the Linguistic intelligence of Howard Gardner. Linguistic intelligence refers to the sensitivity of the spoken and written language, the capability in learning the languages, and the capacity to use these languages in accomplishing specific goals. Furthermore, it includes the ability to use the language effectively in expressing oneself rhetorically or poetically as well as to remember information easily (Smith, 2008). The reason for adopting this theory is that in every society, children begin to communicate with a language at home different from the language they come across in their social world. Chukwu (2011) stated that a child who goes through a learning process seriously needs the usage of the word of his environment. The native language used around him as a context for learning can affect a student's achievements in all areas of knowledge (Leiberman and Hoody, 1998). Cited by Bala (2014), Ricardo et al. conducted on Mother Tongue Based Multilingual Education (MTB-MLE), which resulted in the active participation of the learners. A teacher who participated in the study further explained that MTBMLE quickly eliminates inhibition and fear in many pupils especially the younger ones. It is in these contexts that this study anchored. Figure 1 presents the schematic diagram illustrating the framework of the study.

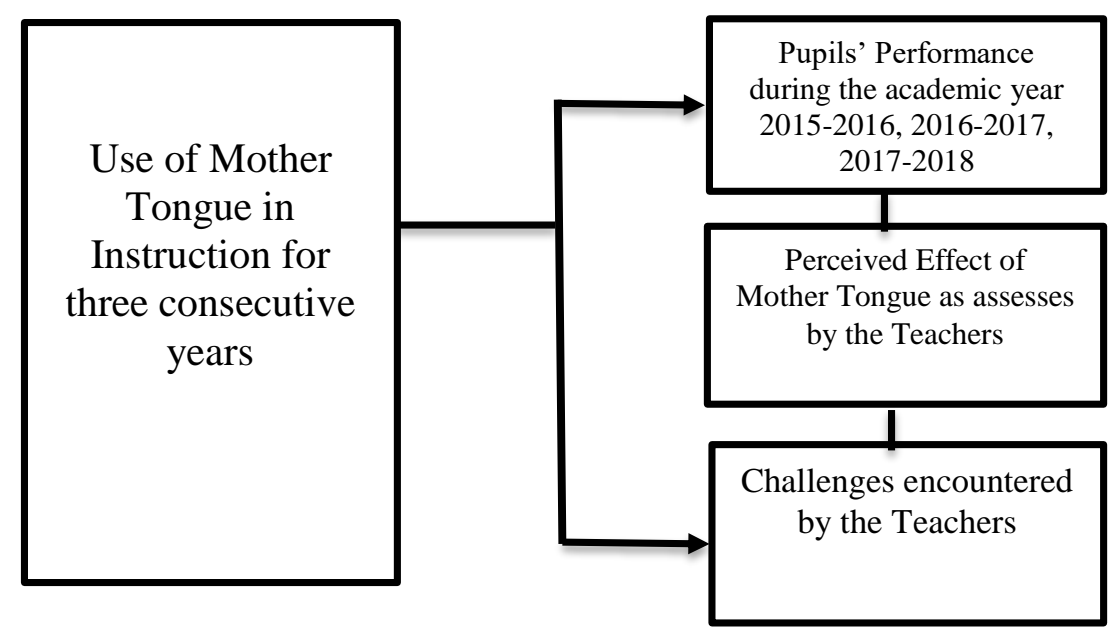

Figure 1: Schematic Diagram Illustrating the Study Variables 


\section{Methodology}

This study used mixed methods in gathering the data. The mixed-method is a combination of quantitative and qualitative methods, approaches, or concepts in a single research study or a set of related studies (Burke, J, \& Christensen, L., 2012). According to (Anderson, 2006) qualitative research is collecting, analyzing, and interpreting data by observing what people do and say whereas, quantitative research refers to counts and measures of things, qualitative research refers to the meanings, concepts, definitions, characteristics, metaphors, symbols, and descriptions of items. In a quantitative method, the pupils' academic performance for three consecutive years analyzed. In qualitative, the researcher conducted the focus group discussion involving the teachers who have the full knowledge of delivering instructions using the mother tongue.

\section{Subjects of The Study}

A purposive sample of 27 pupils who used of mother tongue as medium of instruction, and ten teachers of whom four from grade 1, 3 from grade 2 and 3 from grade 3 levels participated in the study. These teachers delivered instruction with the use of the mother tongue as a medium of instruction.

\section{Data Collection}

The following were methods employed in generating the research data:

1. Documentary Review. Document review is a way of collecting data by reviewing existing documents. In this study, the documents such as pupils' academic performance on the subjects English, Math, ESP, and Araling Panlipunan for the academic year 2015-2016, 2016-2017, \& 2017-2018 in the Division of La Carlota City.

2. Focus Group Discussion. According to Wanjohi (2012), Focus Group Discussion (FGD) is a "method of data collection that used to collect indepth qualitative data in various descriptive studies such as case studies, phenomenological, and naturalistic studies." The main goal of Focus Group Discussion is to provide an opportunity for the participants to talk to one another about a specific area of study. The facilitator is there to guide the discussion. In this study, the focus group discussion provided the direction and support for the assessment. Additionally, the FGD helped the researcher solicit in-depth information on the solutions to the issues faced by the teachers implementing the Mother Tongue Instruction.

The Focus group members consisted of the ten teachers who directly deliver the instruction using the mother tongue.

\section{Ethical Issues}

The teacher participants were informed about the purpose of the research. They participated voluntarily, and they could terminate their participation at any time if they so wished. Permission to conduct the study was granted by the school principal. The anonymity of the subjects and respondents observed.

\section{Results and Discussion}

The findings of the study are as follows:

Figure 2 presents the pupil's academic performance in various subjects with the use of the mother tongue as a medium of instruction for three consecutive years. It shows that pupils' performance in mathematics for three successive years slightly improved with the mean percentage score of $81.11,81.25$, \& 81.49, respectively. In English with an increase of mean percentage score in the academic year 2015-2016 from 81.37 to 87.74 , in ESP, the highest mean percentage score is during the academic year 2016-2017 with 88.59, in the Araling Panlipunan subject, the pupils' academic performance increases with the mean percentage score of $80.44,81.90,83.44$ respectively.

The results imply that pupils perform consistently and slightly improved their performance in mathematics during their grade 1 , grade 2 , and grade 3 . They are because some of them find some difficulty in comprehending directions and mathematical vocabulary with the use of mother tongue as of the medium of instruction used by the teacher. The study of Latu supported this finding. According to her, students are unfamiliar with many mathematical terms and phrases both in the translation in the native language and English (Latu, 2015). The complexities of mathematical sentences shown to provide extra challenges for these students learning. 


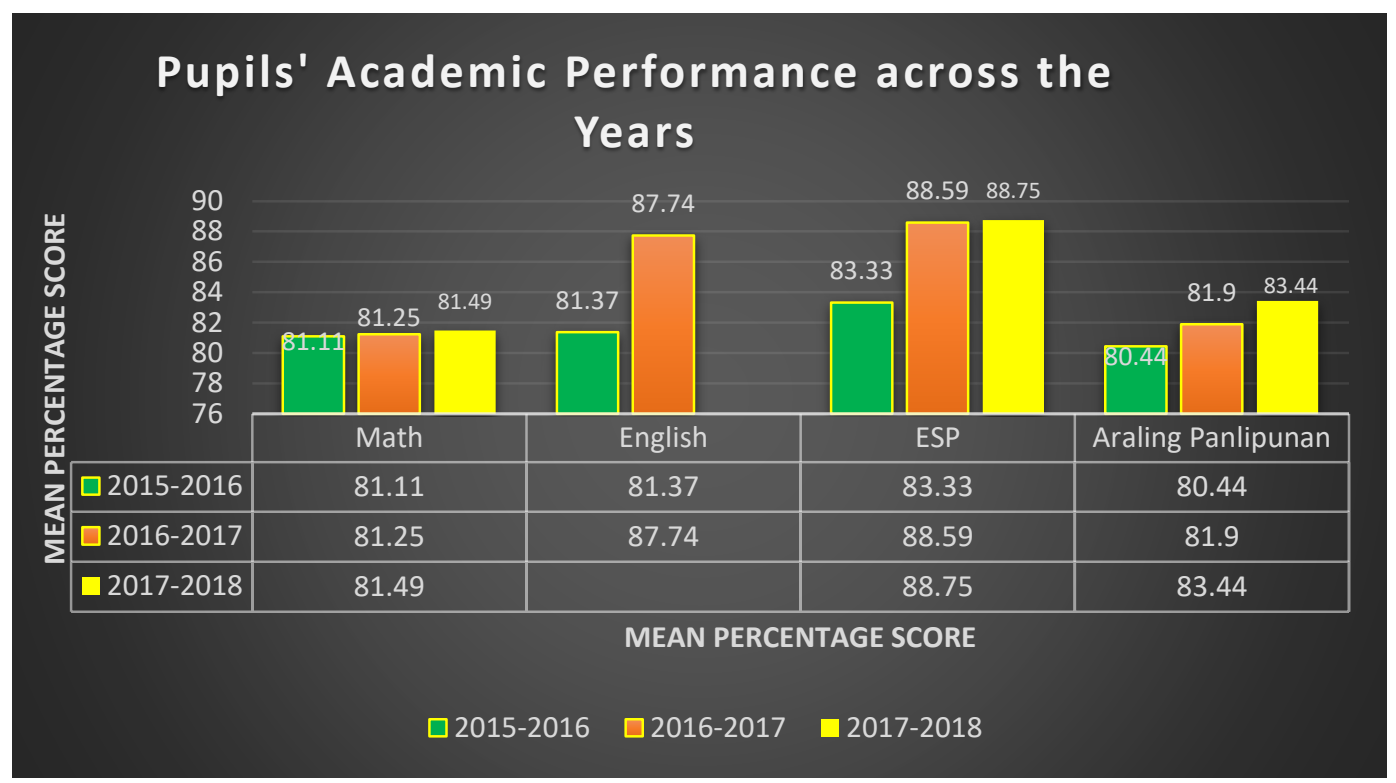

Figure 2: Pupils' Academic Performance across the Years Using the Mother Tongue as Medium of Instruction

\section{The Perceived Effects of Using Mother Tongue as Assessed by Their Teachers}

The use of mother tongue in teaching affects the way pupils learn. The thickness and richness of the field text gathered afforded the identification and emergence of the three themes relative to the effects as observed by the teachers. The observed effects of the mother tongue thematized into cognitive ability, affective ability, and motor skills.

\section{Improved Pupils' Cognitive Ability}

According to Moshman cited by Noormohamadi (2008), the intellectual (cognitive) development is "the emergence of increasingly sophisticated forms or levels of understanding, reasoning, and rationality is an ongoing process of reflection, coordination, and social interaction that begins in early childhood and continues, at least in some cases, long into adulthood." The following responses of the teacher participants below show how the mother tongue improved the pupils' cognitive ability;

T1: The pupils can reason well and can comprehend well in the mother tongue. discussion.

T2: the pupils are more engaged in the class
T3 \& T7: They can express their ideas and opinions freely, can understand, and react more with the situations.

T4: Mother's tongue is a great help in understanding their lessons well.

T5: In general mother tongue helps pupils to improve reasoning, interaction, and comprehension.

T6: Yes, the pupils can express their ideas and feelings through the use of the mother tongue as language.

The statements of the teacher participants indicate the pupils' performance in terms of their cognitive ability. The learners better understand the lessons with the use of the native language. It improves their reasoning skills; it helps them interact meaningfully with the material and comprehend concepts, facts, and even conclude using their language. This observation is similar to Lartec and Belisario's findings of the study. According to Lartec and Belisarios (2014), most pupils respond actively to the discussion when the mother tongue used as a medium of instruction. Still, when the teacher uses English, only two or three take part in the debate. The finding is the same as the study conducted by Bachore (2014). Based on the analysis of their results, the students disclosed that learning in the native language had improved children's participation and interaction. 
The findings imply that the use of the mother tongue in instruction gives a significant opportunity to the students in creating the communicative environment wherein they learn and claim whatever they need in the class and the school compound without any reservation.

\section{Improved Pupils' Affective Ability}

The affective domain Krathwohl, Bloom, Masia (1973) includes "how deals only with things emotionally, such as feelings, values, appreciation, enthusiasms, motivations and attitudes". The use of the mother tongue affects the pupils' performance in terms of their affective domain. According to Benson (2005), the use of the first language improved pupils' affective domain, such as self-confidence, self-esteem, and identity. He stressed out that students increase their motivation and initiative as well as creativity inside the classroom when they are using the native language. Children act naturally and communicate efficiently. Furthermore, the use of mother tongue in the school develops their personalities as well as their intellects, unlike submersion classrooms where they forced to sit silently or repeat mechanically, leading to frustration and, ultimately, repetition, failure, and dropout. the following statements below evident in the responses of the teacher participants such as:

T1\&T7: Develop their self-confidence in doing their tasks.

$$
\begin{aligned}
& \text { T2: Mother's tongue affects the way they feel } \\
& \text { the belongingness because each } \\
& \text { pupil can relate to each other } \\
& \text { using their accustomed } \\
& \text { language. }
\end{aligned}
$$

T3\&T4: Indeed, they enjoy learning by using their native tongue.

T4: They understand the feelings of the others and have fun in using the MTB

T5: they have the confidence in expressing their ideas because they know the language, except for the difficult words

T6. They can get well together, but they use mixed words using MTB\& English.

The participants' statements show how mother tongue develop the pupils' affective ability. It improves their feeling of belongingness, understanding more feelings, needs, and interests of their classmates, and showing of belief that learning is enjoyable and fun using their native language. Similar findings in the study of Ball stated that mother tongue education improves children's self- confidence, self-concept, and identity. Moreover, children gain a better self-concept and have a strong sense of their own identity. Children's home culture and traditional knowledge are validated and reinforced with the use of the mother tongue. Thus, these children who exposed to the mother tongue perform better in school and life than children who forced to learn in an unknown or strange language (Ball, 2010).

\section{Improved Pupils' Motor Skills}

Children expected to develop both their fine and gross motor skills to be efficient and effective movers when engaging in wholesome physical and health activities. They are also likely to acquire an understanding of good health habits and develop their awareness about the importance of safety and how they can prevent danger at home, in school, and in public places (K-12 Kindergarten Curriculum Guide, 2015). In the study of Malone (2003), the reports that the teachers gained confidence from the good results of the new approaches and were willing to take more risks and be more innovative in their teaching. Further, because interactions with their peers and teachers had increased, the children were better able to enjoy learning to read and write (Malone, 2003). The result of observation is clear evidence of the effect of the native language in pupils' motor skills. The following statements coming from the interviewed teacher participants support the claim above.

T1: They can communicate and react freely. They have a sense of creativity and can execute the lessons learned.

T2: They can communicate with fluency using their native language.

T3: They can retell the stories they learned in their language.

T4: They can recite, talk, express themselves, and communicate on their level.

T5: Pupils learn to sing and enjoy the lessons and involve in games.

The statements from the participants indicate the perceived effects of the mother tongue on pupils' psychomotor domain. It helps them learn by doing, talk with fluency, and even execute what they have learned because they understand better the instructions. In the findings of the study of Sario 
(2014), it gleaned from the data that children act naturally to circumstances with their native language. MLE encourages active participation by children in the learning process because they understand what discussed and asked of them. Richardson (2001) underscores the importance of MT in promoting learner's participation. Surprisingly, this result confirmed by the teacher with comparable figures in quantitative data. The other issue related to teaching and learning is measuring students' performance through exams and assignments. Smits et al. (2008) cited that if classroom participation increases, there will be an improvement on the learners' achievement.

\section{The Challenges Encountered by Teachers}

Teachers' general views of these challenges reflected in their perceptions of the feasibility of classroom implementation of MTB. These are a.) Lack of instructional materials in the teaching mother tongue, b.) Lack of translated terms c.) Programmed training. The statements below describe the difficulty encountered by the teachers in implementing the mother tongue.

\section{Lack of Instructional Materials}

Materials for both teachers and students must be available in the language of instruction. To ensure quality materials are available, governments, donors, and non-governmental organizations (NGOs) need to allow for adequate time to develop, pilot test and evaluate mother tongue and second language materials (MTB-MLE Network, 2013).

Statements from the teachers' participants indicate that the most common problem in the implementation of the mother tongue is the lack of materials available for the delivery of instruction.

T1, T7\&T8: There is no reference book written in the native dialect.

T2: In teaching reading, we need to write a Hiligaynon story as our springboard because there is no available reference.

T3\& T5: It is hard to deliver the instruction because there are no available materials written on the native language.

T4\& T6: we lack references or learning materials that will serve as our guide in teaching lessons with the use of the mother tongue.
The responses of the teachers reveal that there are inadequate instructional materials in delivering MTBMLE. These findings supported by the various studies that recently conducted. Materials in teaching MTBMLE teacher's guides are not available yet, too much delayed (Alegada et al. 2014). Teachers also emphasize that they are lacking in reliable references or learning materials that will serve as their guide in conducting the mother tongue inside the classroom (Abano et al. 2014). Teacher explained that they find difficulty in navigating their way through this shift without resources. Materials guide teachers, and they all expressed a hunger for more support in this area. One teacher openly expressed frustration in recalling a phrase used during her training. She quoted that "DepEd says grade one teachers are the champion of change', but how can we be the champions of change if we don't have enough materials and references?" It was the lack of materials available to teachers in the classroom (Burton, 2013).

\section{Lack of Translated Terms}

Teachers as translators of the second language into a native language must have a more profound linguistic and cultural background of their mother tongue than of a second language, which they have to learn to be wellversed in delivering instruction. The translator who translates into his or her native language has a more fundamental and practical knowledge of the various linguistic elements of his or her native language, such as semantics, syntax, morphology, and lexicology than the translator who translates into a foreign language. In this respect, Dickins (2005) points out. In essence, translator training usually focuses on translation into the mother tongue because of the higher quality achieved in that direction than in translating into a foreign language. But this is contrary to the local situation wherein some teachers have limited vocabulary in the mother tongue. The following statement serves as evidence;

T1: Some words are difficult to understand or unfamiliar words, which cause hindrance in discussing the lesson.

T2: I find it difficult to translate some words in English to Hiligaynon because of a lack of vocabulary.

T3: In teaching Mathematics, there are terms in a word problem that I can't translate into a specific term in Hiligaynon because I don't know.

T4 \&T5: It is hard for us to translate or bridge Hiligaynon words to the English 
language. It is not an easy task for the teachers.

T6\&T7: Mother's tongue is also tiresome for us to use because words in the first language are usually longer, especially when we are telling a story and discussing it in numerical forms. Sometimes, we run out of vocabulary.

T8\&T9: There are terms in Hiligaynon that so unfamiliar and very deep in meaning that we teachers can't find the right meaning.

T10: Pupils who have to learn some terms in English have difficulty in translating and comprehending to the local dialect.

Teachers' responses indicate that even though they are teachers, they don't have enough vocabulary in delivering lessons with the use of mother tongue as a medium of instruction. Also, the participants are experiencing difficulties in teaching their pupils because they cannot think of the right term in Hiligaynon that is precisely the same as the second language. This scenario put teachers into the situation that confuse the pupils. In the study of (Burton 2013), a group of teachers expressed exasperation as one person said, -Even I do not know the Bikol for exponent or logarithm. Math and science terms consistently highlighted as the most challenging areas for using the mother tongue. According to (Latu 2015), one of these difficulties arises when their first language does not have the vocabulary to express the mathematical ideas that they learn in the classroom. Mathematics vocabulary includes words that are specific to mathematics, such as divisor, denominator, quotient, and coefficient.

\section{Programmed Training}

As countries and communities increase mother tongue-based multilingual educational programs and improve their quality, the teacher preparation curriculum must evolve. Curriculum review and revision, and regular training for instructors at teacher training institutions is essential to the success of multilingual school programming. For teachers in MTB MLE classrooms to help their students achieve a successful education, the teachers must understand and follow two specific pedagogical approaches (Malone, 2011). The implementation of the MTBMLE in the Philippine Educational setting, various training conducted, but still, there are some challenges encountered by the teachers. Statements below are the evidence of their hardship;
T1: Only a few teachers sent to the national seminar for direct training.

T2: I once sent to the national seminar, but there is no follow-up training.

T3. The interpretation of the implementation of MTB-MLE varies because of different sources of information.

T4: I implement a mother tongue, but I only attended the local seminar.

T5: This is my first time to teach mother tongue, so I just ask my co-teachers how to deliver it.

Training and seminars are essential for teachers who are teaching multilingual learners because they need to be oriented and guided on how to handle learners with different languages. Also, through training and seminars, the teacher's knowledge is enriched because they involved in various workshops during workshops. Lessons and training also served as an opportunity for the teachers to learn from and interact with the different participants (Lartec \& Belisario, 2014). Mackenzie (2015) cited that teacher training needs to acknowledge the importance of linguistic diversity and should support teachers to implement methodologies that use the languages of the learner. This kind of approach will be a challenge to the (often) centralized approaches to teacher development and deployment. Countries should work with teacher organizations - unions and professional councils - to develop processes to recruit and train teachers appropriately.

\section{Conclusion}

The following conclusion was drawn based on the findings of the study:

The academic performance of the pupils in various subjects using the mother tongue for the three consecutive years improved.

The use of mother tongue as a medium of instruction affects pupils' performance in terms of their cognitive ability, affective ability, and motor skills. The pupils participate actively during the class discussion and interact with each other with confidence.

Teachers experience some problems in the implementation of the mother tongue. Nevertheless, these did not hinder them from delivering quality instruction. 


\section{Recommendations}

It is, therefore recommended:

Teachers should strictly implement the use of the mother tongue as a medium of instruction since the learners can express their ideas well and think without hesitation and with confidence. They must have done proper translation so that the pupils will not be confused about the ideas presented. The language facilitates comprehension and easy recalling of terms as they are more familiar with it.

Improvisations of instructional materials should be done by the teachers to address the problems to enhance pupils' learning. The materials, such as references and dictionaries, are a big help in facilitating the teaching-learning process.

Higher Learning Institutions as producers of globallycompetitive professional teachers in the elementary should revisit its curriculum in teacher education, particularly in the subject Teaching Mother Tongue to develop the student's skills and ability in the teaching mother tongue.

\section{References}

1. Abano, S. G., (2014). "MTB-MLE: A Solution or A Hindrance in Promoting Quality Instruction." Carlos Hilado Memorial State College Talisay City: Unpublished Thesis.

2. Agarwal, Nidhi and Jaiswal, Sushma, (2019). "A Study at organizational commitment of educator in school". International Journal of Multidisciplinary Education and Research, 2019, 4(1), 39-41; doi: 10.5281/zenodo. 3806468 .

3. Agarwal, Nidhi and Kumar, Puneet, (2009). "Role of Information Technology in Education", AICTE Sponsored National Conference on Information Integrity \& Supply Chain Management Abstracts Proceeding, Book World Publisher, Dehradun, pp 18.

4. Alegada, Bayon-On, Bustamante, Cabahug \& Dullas, (2014). Push And Pull In The Utilization Of Mother Tongue As Language Instruction. Carlos Hilado Memorial State College Talisay City: Unpublished Thesis.
5. Anderson, J. D., (2006). Icoe.Org. Retrieved From Https://Www.Icoe.Org/Webfm Send/1936 On January 30, 2015.

6. Bachore, M. M., (2014). Learners' Success In Mother Tongue Based Classroom Instruction And The Attitudes And Perceptions Of School Communities. Rise - International Journal Of Sociology Of Education Vol. 3 No. 2, 118-135.

7. Bala, Saudat, (2014). The Use Of Mother Tongue As A Means Of Communication In The Enhancement Of Science Learning In Primary Schools: The Nigerian Situation, Department Of Integrated Science, Federal College Of Education, Kano State, Nigeria. Primary/Ece/Elementary School Science Education Retrieved From Http://Stemstates.Org/Assets/Files/262 _Saudat\%20shehu\%20full\%20paper.Pdf On January 23, 2016.

8. Ball, J., (2010). Enhancing The Learning Of Children From Diverse Language Backgrounds: Mother Tongue-Based Bilingual Or Multilingual Education In The Early Years, Unesco. Http://Unesdoc.Unesco.Org/Imag

9. Benson, C., (2005). The Importance of Mother Tongue-Based Schooling For Educational Quality. Stockholm University: Unesco Efa Global Monitoring Report 2005, The Quality Imperative.

10. Burton, L. A., (May 2013). Mother TongueBased Multilingual Education In The Philippines: Studying Top-Down Policy Implementation From The Bottom Up. University Of Minnesota, United States Of America.

11. Christensen, J., (2012). Educational Research (Quantitative, Qualitative, And Mixed Approaches) Fourth Edition. United States Of America: Sage Publications, Inc.

12. Chukwu, M. N., (2011). Importance Of Language In The Education Of A Child And Literacy Art. Knowledge Review. 23(2): 155 $-158$.

13. Dickins J., et al., (Te2005) Thinking Arabic Translation: A Course In Translation Method: Arabic To English, Oxon: Routledge.

14. K-12 Kindergarten Curriculum Guide. (July 2015). Development Domains. Retrieved From

Http://Www.Deped.Gov.Ph/Sites/Default/Fi les/Page/2015/Kindergarten\%20cg\%0july\% 202015.Pdf 
15. Kocakulah, S. U., (2005). The Effect Of Teaching In Native And Foreign Language On Students' Conceptual Understanding In Science Courses. Asia-Pacific Forum On Science Learning And Teaching, Volume 6, Issue 2.

16. Kumar, Rajeev, (2019). "Designs for Quality Enrichment in Higher Education". Globus An International Journal of Management \& IT, 11(1); 43-46, ISSN: 0975-721X.

17. Krathwohl, D.R., Bloom, B.S., Masia, B.B., (1973). Taxonomy of Educational Objectives, The Classification Of Educational Goals. Handbook Ii: Affective Domain. New York: David Mckay Co., Inc.

18. Lartec, J. \& Belisario, K., (2014). Strategies And Problems Encountered By Teachers In Implementing Mother Tongue - Based Instruction In A Multilingual Classroom. The Iafor Journal Of Language Learning Volume I - Issue I -, 1-16.

19. Latu, V. F., (2015). Language Factors That Affect Mathematics Teaching And Learning Of Pasifika Students. Retrieved From Http://Www.Academia.Edu/1593857/Langu age_Factors_That_Affect_Mathematics_Tea ching_And_Learning_Of_Pasifika_Students

20. Leiberman, A., And Hoody, M.A., (1998). Using The Environment As An Integrating Context For Learning.Www.Seer.Org/Pages/ Execusum.Html

21. Lewis, P., Simons, G. \& Fennig, C., (Eds.). (2013). Ethnologue: Languages of The World. (17th Ed.) Dallas, Texas: Sil International. Retrieved March 1, 2016, From Http://Www.Ethnologue.Com Lincoln, Y. S. \& Guba, E. G. (1985).

22. Mackenzie, P. A., (2015). Global Campaign For Education. Retrieved From Http://Www.Campaignforeducation.Org/Do cs/Reports/Gce\%20mother\%20tongue_En.P df. On January 30, 2015

23. Malone, S., (2011). Teacher Education For Mother Tonguelbased Education Programs. Retrieved

From Http://Www.Sil.Org/Sites/Default/Files/File s/Institutionalizing_Teacher_Training_For_ Mtb_Mle_12-2011.Pdf On January 28, 2015

24. Maajeeny, Hassan, (2019). " Children with Emotional and Behavioral Disorders in Saudi Arabia: A Teacher Preliminary Screening".
Globus Journal of Progressive Education, 9(2); 4-10, doi: 10.46360/globus.9.2.2020.410.

25. Mtb-Mle Network, (2013). Improving Learning Outcomes Through Mother Tongue-Based Education. Retrieved From Https:/Www.Eddataglobal.Org/Documents/ Index.Cfm/Mother\%20tongue-

Based \%20instruction\%20and\%20learning\% 20outcomes_Final_Updated\%20jan\%20201 3.Pdf

26. Noormohamadi, R., (2008). Mother Tongue, A Necessary Step To Intellectual Development. Pan-Pacific Association of Applied Linguistics, 25-36.

27. Philippines Department of Education, (2009). Institutionalizing Mother TongueBased Multilingual Education (Order No. 74), Pasig City.

28. Philippines Department of Education, (2012). Guidelines On The Implementation Of The Mother Tongue-Based Multilingual Education (Mtb-Mle) (Order No. 16), Pasig City.

29. Richardson, V., (Ed) (2001). Handbook of Research on Teaching, Fourth Edition. Washington Dc: American Educational Research Association

30. Sario, M. L., (2014). Behavior Manifestations Of Pupils Using Mother Tongue In The Classroom. International Refereed Research Journal, www.researchersworld.com, V(3); 901.

31. Smith, Mark K. (2008) 'Howard Gardner and multiple intelligences,' the encyclopedia of informal education, http://www.infed.org /mobi/howard-gardner-multipleintelligences-and-education.

32. Smits, J.J., Huisman, et al., (2008). Home language and education in the developing world, UNESCO. http://unesdoc.unesco.org/ images/0017/001787/178702e.pdf.

33. UNICEF, (2011). Action research on mother tongue-based bilingual education: Achieving quality, equitable education. http://www.vn.one.un.org.

34. Wanjohi, Anthony M., (2012). Kenya Project Organization, Retrieved March 30, 2013, from http://www.kenpro.org/focus-groupdiscussion-method-of-data-collection/ 